\title{
APLICABILIDADE DAS TEORIAS DE ENFERMAGEM
}

\author{
Mariana Fernandes de Souza*
}

SOUZA, Mariana Fernandes de. Aplicabilidade das teorias de enfermagem. Rev. Esc. Enf. USP, São Paulo, 22 ( $n .^{\circ}$ especial): 62-67, Jun. 1988.

Neste trabalho são feitas considerações sobre a necessidade interna que tem o ser humano de conhecer, de explicar a realidade com a qual se relaciona, ou seja de teorizar. A seguir são abordados alguns questionamentos existentes sobre teorias em enfermagem, bem como sobre sua aplicabilidade prática.

UNITERMOS: Teorias de enfermagem. Filosofia de enfermagem.

O tema teoria é complexo e tem uma relevância, uma importância intrínseca que não são diminuidas pelo nosso pouco saber e não aceitação do mesmo, ou pelo mau uso que dele se possa fazer. Consciente das limitações que possuo no conhecimento e principalmente na experiência em utilizar, testar na prática as assim denominadas teorias de enfermagem, proponho-me a colocar algumas reflexões e resultados de vivências no assunto, esperando merecer a análise e a crítica de colegas interessados em contribuir para o crescimento da enfermagem.

Na primeira parte desta exposição, serão colocadas idéias gerais sobre a necessidade de concepção da realidade (o teorizar) e seu significado. Teceremos algumas considerações baseadas em autores consultados e em questionamentos que nos vêm sendo propostos por alunos, colegas e que a nós mesmos se apresentam ao longo da busca no aprendizado do assunto em questão. $\mathrm{Na}$ segunda parte, procuraremos discutir a aplicabilidade das "teorias" de enfermagem, relacionando-a às colocações da parte anterior.

1 - O ser humano tem uma necessidade interna de conhecer, de explicar a circunstância em que vive - a realidade com a qual se relaciona. Seria impossível este relacionamento sem uma concepção, um modelo desta realidade, pois não haveria um guia, um ponto de referência para abordá-la. Este esforço de explicação é uma forma de organizar, de construir o mundo ,o real que nos é dado perceber. A realidade porém, não se esgota e nem se deixa aprisionar em um modo de explicação, em um modelo, ou em uma teoria. Ela é muito mais rica que estes. Dada a sua

- Enfermelra, Professor Adjunto do Departamento de Enfermagem da Escola Paullsta de Mediclna - São Paulo. 
multi-dimensionalidade, ela pode ser abordada de vários modos, sob várias perspectivas. Cada perspectiva capta fenôinenos que considera relevantes e os organiza, interrelaciona, formando um quadro de referência para lidar com a realidade.

Segundo DEMO (1981), "Abordagem quer dizer o modo pelo qual o cientista se aproxima em termos teóricos do objeto, no sentido preciso de instrumental conceitual do qual se serve para realizar sua atividade científica... Podemos distinguir, em termos esquemáticos e sempre simplificadores, seis tipos específicos de abordagem: empirismo, positivismo, funcionalismo, sistemismo, dialética e estruturalismo. Ainda observa este mesmo autor que: "mesmo sendo correto assumir que cada abordagem não passa de uma das maneiras de construir o real, cada uma delas, tomada isoladamente, esconde a pretensão de tudo explicar e de superar todas as outras concorrentes". Ainda mais, além da pluralidade de modos, demonstra a impossibilidade de cxplicação exaustiva e unificada de cada modo, quando o autor acima citado afirma que "não existe "a" abordagem pura, mas sempre muitas versões dela" e exemplifica: "Há a dialética de estílo soviético, de estílo chinês, de estílo iuguslavo, de estílo hegeliano, etc., que nem sempre são complementares, mas exatamente antagônicas."

SANTOS (1984) falando sobre teoria do conhecimento, expõe a problematicidade deste que de modo geral é uma relação que se estabelece entre um sujeito e um objeto. $\mathrm{O}$ sujeito no ato de conhecer não faz a simples reprodução de uma realidade fixa, ordenada e estruturada, "pelo contrário, ela surge como algo desorganizado, caótico que oferece uma multiplicidade, assustadora de impressões intercruzadas que devem ser ordenadas e estruturadas para se transformarem em conhecimento." E quando o sujeito estrutura, organiza a realidade, para conhecê-la, surge uma série de indagações sobre os elementos que utilizou para essa estruturação, sobre a adequação dos mesmos e sobre a confiabilidade dos resultados obtidos.

Diante das incertezas na construção do conhecimento, surge o auxílio da crítica, mesmo sabendo que esta não é simples nem fácil de ser exercida, pois como diz DEMO (1981), "na prática sempre deturpamos as abordagens alheias quando as criticamos, porque não saberiamos partir de um ponto de vista que não o nosso". Falando sobre a diversidade de pontos de vista, ou abordagens, este autor explica que mesmo a rigidez das posições, não impede a construção da ciência, "antes reforça sobremaneira a necessidade do diálogo crítico, único critério que consegue ser comum". Diz ainda a este respeito que na crítica, no estudo das abordagens contrárias é possível "aprender dos adversários e até mesmo a eles aderir", e que "muito raramente o bom cientista é aquele que defende rigidamente sua posição, como se os outros só pudessem estar errados".

No contexto destas idéias, podemos vislumbrar que o ser humano é muito limitado e que a realidade não é totalmente devassada por ele, por ser inesgotável e inacabada; por isto a explicação, a organização, ou seja, a teoria, nunca é definitiva, mas deve estar sempre em processo de reformulação. 
Em que pesem, porém, as contingências do processo, se as teorias forem elaboradas dentro de rigor metodológico, elas são uma necessidade se quisermos: superar o senso comum, analisar em profundidade, ter cuidado com a argumentação e principalmente fundamentar uma prática crítica.

No que concerne à prática, nunca é demais lembrar que "teorico" não significa desligado da prática. A reflexão, a construção teórica tem como marca própria a abstração, o encadeamento de idéias, porém, ambos surgem do real, da prática, sendo esta o fundamento, o pressuposto da teoria. No dizer de PEREIRA (1982), para refletir, pensar a sua prática o homem tem que se abstrair, mas ele não teoriza no vazio, como se realizasse um ato intelectual isolado, mas é um ato do homem como um todo em relação com o mundo. E uma prática desligada da teoria não seria uma ação consciente, transformadora. "A atividade humana precisa de um respaldo teórico, crítico, tanto para os avanços dos projetos humanos como para que nos livremos da mediocridade."

A construção teórica deve ser sempre contrastada com o real, com a prática num constante processo de renovação, pois "para uma boa teoria é essencial a prática, e para uma boa prática é essencial a teoria" (DEMO, 1985).

Outra marca própria da teoria é ser universal, o que não deve ser confundido com impossibilidade de historicidade. Mais uma vez, buscamos a autoridade de DEMO $(1981,1984)$ o qual coloca com profundidade de reflexão e consistência de argumentos ser a teoria generalizante, elaborada a partir de conceitos que são abstraçōes que dizem respeito a todos os casos concretos cobertos por eles, não sendo nenhum deles em particular. Daí advem o caráter universalizante da teoria $e$, se assim não fosse, não seria teoria. A prática, o uso da teoria numa situação concreta, é que a torna histórica. A prática, portanto, é condição de historicidade da teoria. E como a teoria é universal, generalizante, praticam-se versões concretas da teoria e não toda a teoria. Por isto, toda prática "apequena" a teoria, porque não passa de uma versão histórica dela. "Assim, toda prática, ao mesmo tempo que realiza a teoria, também a limita, no sentido de que não consegue esgotar todas as potencialidades teóricas".

II - A busca de estruturação, de organização dos elementos constituintes da realidade profissional de enfermagem é um empreendimento que vem se fazendo através dos anos e que se direcionou para a elaboração de modelos conceituais e teorias desde há cerca de três décadas. Participamos da opinião de enfermeiras que consideram não haver ainda propriamente teorias na enfermagem. FAWCETT (1984) coloca o desenvolvimento do conhecimento de uma disciplina em uma hierarquia estrutural cuja ordem é: metaparadigma, paradigma ou modelo conceitual e teoria. Pensamos que o estágio de desenvolvimento atingido pela maoiria da produção de enfermagem até o momento, é o de modelo conceitual ou paradigma. Há até opiniões, como a de HARDY (1978) de que o conhecimento na enfermagem ainda está na fase de pré-paradigma, apresentando todas as 
irregularidades e inconsistências desta fase. O modelo conceitual é uma organização que provê uma forma de referência para os profissionais, mas ele é composto por um encadeamento de conceitos expresso de forma geral, ainda não tão elaborada. A teoria é a maneira menos geral, mais desenvolvida e mais específica de organização dos conceitos. Já tivemos a oportunidade de nos deter mais neste assunto em dois trabalhos: SOUZA (1984, 1985). No momento, só queremos ressaltar a importância de se considerar o nivel alcançado pelo trabalho de organização teórica na enfermagem, porque a expectativa de aplicação, a busca de um guia na mesma tem que ser adequada ao alcance dela. Esperar obter de um modelo conceitual aplicações que só a teoria seria capaz de oferecer, é inadequado e frustrante.

Verifica-se que muitas autoras americanas que denominam seus trabalhos de modelos conceituais, usam a expressão desenvolvimento de "teorias" para designar o trabalho que vêm realizando na estruturação do conhecimento, ou seja, são teorias em processo de elaboração. Isto não diminui o valor dessa produção. É impossível esperar um caminho diferente (disciplinas hoje bem desenvolvidas passaram pelas mesmas etapas), principalmente se considerarmos a problemática que sempre existiu no contexto da enfermagem. OLIVEIRA (1985), tratando da formação do conhecimento científico, aponta a necessidade de delimitação do campo, do objeto e do método de estudo e observa o seguinte: "Quando, porém se trata do estudo de uma ciência em formação, com matéria ou objeto ainda em busca de delimitação, o caminho tem sido trabalharem-se conceitos centrais em modelos teóricos ou paradigmas que procurem guiar o conhecimento da realidade." Esta é a situação da enfermagem que está evoluindo na formação do seu campo de conhecimento.

KING (1981) e OREM (1985) já derivaram teorias de seus modelos conceituais. Julgamos, porém, que estas teorias propostas carecem muito ainda de serem contrastadas com a realidade, de serem submetidas a testes, o que parece estar sendo feito em pequena quantidade mesmo no país onde se originaram. Lembramos aqui que testagem, ou busca de comprovação de teoria não é um processo estático, de resultado final, mas é dinâmico, contínuo e sempre passível de reformulação e progresso.

Quando queremos aplicar esses trabalhos, temos que analisar o potencial de utilidade deles na prática, na pesquisa e na educação em enfermagem. Fica evidente a necessidade de maior elaboração para que eles passem do nível mais geral para um mais específico, quando buscamos o embasamento para prescrição capaz de afetar a prática ,a possibilidade de definições operacionais e de indicadores empíricos para pesquisa e a derivação de premissas nas quais fundamentar a construção de um currículo. Porém, eles só evoluirão se forem utilizados. É a procura de desenvolver mais suas proposições, de elaborar atividades assistenciais neles baseadas, de selecionar aspectos a serem observados para a identificação de conceitos, de aplicá-los como roteiros gerais para o conteúdo curricular e atividades de ensino e aprendizagem, que fará emergir as 
lacunas, as imprecisões e as reformulações necessárias a caminho da precisão teórica.

A objeção que é feita com freqüência é a de que a maioria desses modelos são de origem americana, portanto, não aplicáveis à nossa realidade. Gostariamos de fazer algumas ponderações a esse respeito. Todos os modelos conceituais e teorias já propostos, contém conceitos centrais e constituintes da enfermagem em âmbito universal, ou seja: tratam do ser humano, ambiente, enfermagem, saúde, enfermidade. $O$ interrelacionamento desses conceitos foi feito com base na vivência profissional de cada autora, representando o modo como vêem a enfermagem. Julgamos possam ser aplicados em qualquer lugar onde existir enfermagem. Lembramos novamente que modelos conceituais e teorias são universais por natureza, o que se reveste de historicidade é a aplicação prática dos mesmos.

Um dos modelos mais freqüentemente contestados é o de Dorothea Orem, surgindo sempre a observação de que as proposições de autocuidado têm aplicação só na sociedade americana que tem como um dos valores básicos a independência. Se examinarmos com cuidado as proposições de Orem, podemos concluir que elas não contêm incongruências com o que se espera do ser humano, com a sua dignidade, na provisão dos próprios cuidados, de poder executar suas funções, ou de receber cuidados quando deles necessitar. Será que o homem brasileiro que sofre as limitações do sub desenvolvimento, de doenças, de saber usar seus direjtos (muitas vezes nem sabe que os tem...), não é justamente o que mais necessita de aprender e de valorizar seu auto-cuidado? A aplicação dessas proposições na estrutura social brasileira faria surgir as variáveis que interferem no processo de auto-cuidado do homem brasileiro. As proposições do modelo e das teorias elaboradas pela autora, são, porém válidas de modo generalizante.

Pensamos que a maioria dos modelos conceituais que conhecemos podem ser examinados sob essa mesma perspectiva.

Outro ponto a considerar é a situação do exercício da enfermagem brasileira, com suas dificuldades advindas de problemática sócio-econômica, política e de variedade de preparo das pessoas que a exercem. Pensamos que realmente existem muitos entraves à utilização do saber teórico na nossa realidade. Mas eles não o tornam inviável. A dificuldade existe para qualquer tipo de saber no qual queiramos fundamentar os cuidados de enfermagem.

Finalizando nossa exposição, deixamos claro crer que o ser humano não se esgota na dimensão racional, científica. Acreditamos também, ser a ciência passível de defeitos, de distorções e de ser mal usada. Mas inegavelmente, ela é uma das produções humanas e que, se bem usada, pode muito contribuir para a felicidade do homem. 
SOUZA, M. F. de. Nursing theories applicability. Rev. Esc. Ent. USP, São Paulo, 22 (special issue): 62-67, June 1988.

This paper presents a number of considerations related to the inner need of the human being of knowing and reasonig the environment with which he interacts, as he or she theorizes. Hence several existing issues in nursing theories are approached and the aplicability of nursing theories in practice is also approached.

UNITERMS: Nursing theory. Philosophy, Nursing.

\section{REFERENCIAS BIBLIOGRAFICAS}

DEMO, P. Metodologia cientifica em clências soclals. Sāo Paulo, Atlas, 1981.

. Elementos metodológicos da pesquisa participante. In: BRANDAO, C. R. Repensando a pesquisa participante. São Paulo, Brasillienso, 1984.

. Ciênclas socials e qualidade. São Paulo, ALMED, 1985.

. Teoria - por quê? In: Simpósio Brasileiro de Teorlas de Enfermagem, 1. Florianópolis, 1985. Anais. Florianópolis, Ed. da UFSC, 1985 . p. 52-68.

FAWCETT, J. Analysis and evaluation of conceptual models of nursing. Philadelphia, F. A. Davis, 1984.

HARDY, M. E. Perpectives on nursing theory. ANS., Germantown, 1 (1):37-48, Oct. 1978.

KING, I. M. A theory for nursing: systems, concepts, process. New York, John Wiley, 1981.

OLIVEIRA, M. I. R. A formação do conhecimento e a enfermagem brasileira. In: SIMPOSIO BRASILEIRO DE TEORIAS DE ENFERMAGEM, 1., Florianópolis, 1985. Anais. Florianópolis, Ed. da UFSC, 1985 . p. 7-26.

OREM, D. E. Nursing: concepts of practice. New York, Mcgraw-Hill Book, 1985.

PEREIRA, O. O que é teoria. São Paulo, Brasiliense, 1982.

SANTOS, I. R. Teoria do conhecimento e pesquisa social. In: SEMINARIO NACIONAL DE PESQUISA EM ENFERMAGEM, 3.․, Florianópolis, 1984. Anals. Florianópolis, Ed. da UFSC, 1984, p. 30-42.

SOUZA, M.F. Referencial teórico. Rev. Esc. Enf. USP, São Paulo, 18 (3): 223-234, dez. 1984.

Comentário sobre o tema: desenvolvimento de teorias de enfermagem da Dra. Afaf I. Meleis. In: SIMPOSIO BRASILEIRO DE TEORIAS DE ENFERMAGEM, 1. Florianópolis, 1985. Anais. Florianópolis, Ed. da UFSC, 1985. p. 165-177. 